ISSN: 1130-3743 - e-ISSN: 2386-5660

DOI: http://dx.doi.org/10.14201/teoredu201628293112

\title{
EL ABURRIMIENTO COMO COMPETENCIA: EDUCACIÓN PARA UN MUNDO SOBRESTIMULADO
}

\author{
Boredom as a competence: education \\ for an overstimulated world
}

\section{L'ennui en tant que compétence: éducation pour un monde byperstimulé}

\author{
Alberto SÁNCHEZ ROJO \\ Universidad Pontificia de Comillas. Facultad de Ciencias Humanas y Sociales. \\ Departamento de Educación. Métodos de Investigación y Evaluación. \\ C/Universidad Comillas, 3. 28049 Madrid.asrojo@comillas.edu
}

Fecha de recepción: enero de 2016

Fecha de aceptación: marzo de 2016

RESUMEN

El aburrimiento en tanto que sentimiento de apatía e indiferencia es normalmente vivido como experiencia negativa. De hecho, desde un punto de vista educativo, se ha considerado tradicionalmente la necesidad de erradicarlo. Ahora bien, ésta no es la única manera de entenderlo. Un análisis más profundo puede llevarnos a encontrar en él ciertos aspectos positivos. Desde una perspectiva filosóficoeducativa y, por tanto, fundamentalmente a través del análisis crítico de textos, este artículo analizará en detalle dichos aspectos. Mostraremos que el aburrimiento no es otra cosa que tiempo para uno mismo, el cual es esencial para el desarrollo de la auténtica subjetividad. La sociedad del conocimiento exige individuos autónomos y responsables, pero paradójicamente siempre está ocupando nuestro tiempo. Así pues, con el fin de solventar esta paradoja, concluiremos que el aburrimiento debe ser considerado en la actualidad como competencia básica y fundamental. 
Palabras clave: filosofía de la educación; sociedad del conocimiento; formación; aburrimiento.

\section{SUMMARY}

Boredom as a feeling of apathy and indifference is normally lived as a negative experience. On fact, from an educational point of view, the necessity of eradicating it has been traditionally considered. However, this is not the only way of understanding it. A deeper analysis can lead us to find some positive aspects on it. From a philosophical-educational perspective, and thus by means of critical analysis of texts, this paper will analyze in detail these aspects. We will show that boredom is nothing but time for oneself, which it is essential for the authentic subjectivity development. The knowledge society demands autonomous and responsible individuals, but it is always paradoxically occupying our time. So in order to solve this paradox, we conclude that boredom must be currently considered as a basic and fundamental competence.

Key words: educational philosophy; knowledge society; training; boredom.

\section{SOMMAIRE}

L'ennui, ce sentiment d'apathie et d'indifférence, est généralement vécu comme une expérience négative. D'ailleurs, d'un point de vue éducatif, on a souvent considéré nécessaire son éradication. Pourtant, ce n'est pas la seule manière de l'entendre: une analyse plus profonde de l'ennui peut nous mener à identifier certains aspects positifs. Depuis une perspective philosophico-éducative, donc fondamentalement par le biais de l'analyse critique de textes, cet article propose d'approfondir certains de ces aspects. Il s'agit de montrer que l'ennui n'est autre chose que du temps pour soi, essentiel au développement d'une subjectivité authentique. La société de la connaissance réclame des individus autonomes et responsables, mais paradoxalement elle occupe tout notre temps. Ainsi, dans le but de résoudre ce paradoxe, nous conclurons que l'ennui doit être considéré de nos jours en tant que compétence basique et fondamentale.

Mots clés: philosophie de l'éducation; société de la connaissance; formation; ennui.

TEODORO: ¿Es que no tenemos tiempo libre, Sócrates? Platón, Teeteto

Cuando el diablo no tiene que hacer, con el rabo mata moscas (Refranero Popular) 
ALBERTO SÁNCHEZ ROJO

\section{INTRODUCCIÓN}

Todos nos hemos aburrido alguna vez. Todos hemos experimentado esa sensación incómoda y pesada que nos hace bostezar, perder la atención y, por instantes, sentirnos del todo vacíos. Son momentos en los que no sabemos muy bien qué hacer, lo único de lo que estamos convencidos es de que no nos sentimos a gusto haciendo lo que hacemos ni estando donde estamos. Nuestra reacción puede ser variada. Unas veces es cierta inquietud lo que recorre nuestro cuerpo. Miramos el reloj constantemente, damos golpecitos en la mesa o jugamos absurdamente con cualquier cosa que tengamos en las manos. No dejamos de pensar en cómo salir de allí, pues creemos que bastará con cambiar de actividad para dejar de sentir ese pesar. Otras veces, en cambio, no es la inquietud sino la apatía lo que inunda todo nuestro ser. La situación nos arrastra y ni siquiera nos paramos a pensar en cómo salir de ella. Estamos desganados, incluso llegamos a creer que no tiene que ver con lo que hagamos o con dónde nos encontremos, sino que el problema se halla en nosotros mismos. Esto hace que el aburrimiento, cuando no es circunstancial, pueda ser interpretado patológicamente; esto es, como enfermedad mental.

Sea como fuere, tradicionalmente ha sido considerado como algo de lo que hay que huir. No sólo por el pesar que produce en quien lo padece, sino también porque, tal y como decía el filósofo francés Vladimir Jankélevitch (1989, 153), "por muy átono que sea, el tiempo del aburrimiento [es] un tiempo caracterizado, calificado y relativamente acentuado frente a lo serio». Efectivamente, quien se aburre no se ocupa de lo que en ese momento se tiene que ocupar. Ya sea en el trabajo, en la escuela o en la vida más privada y familiar, quien se aburre de lo que está viviendo no puede tomárselo en serio. El aburrido es el desocupado que, debido a ello, se torna despreocupado. Es un irresponsable, incapaz de dar respuesta a lo que no le causa sino indiferencia.

Por todo ello, desde un punto de vista educativo, el aburrimiento ha sido siempre entendido como un problema importante a resolver. Buscamos formar sujetos activos y participativos, responsables y conscientes del mundo que les ha tocado vivir; de sus ventajas, sus inconvenientes, así como de las posibilidades que presenta. Nadie querría, en principio, legar las riendas del mundo a aquel que tiende a aburrirse, pues representa todo lo contrario de lo que para el mundo deseamos. El aburrido no está atento, se ve desganado, sin voluntad para participar, se encuentra invadido por una indiferencia que le hace ser un inconsciente; capaz de ser y de hacer todo y nada, pues todo parece darle igual y aparentemente nada le importa. Padres y educadores llevan años luchando sin éxito para erradicarlo del proceso de formación de sus hijos y alumnos; sobre todo desde que, lo que apenas era una intuición, adquirió, gracias a la psicología, carácter científico demostrado. Ahora bien, tal y como veremos, ésta no es la única forma de entenderlo. Paradójicamente, aburrirse puede llegar a suponer una experiencia educativamente esencial y es esto precisamente lo que este trabajo pretende mostrar.

El artículo se divide en tres partes. La primera analizará en detalle, desde un punto de vista psicológico, el aburrimiento en cuanto experiencia puramente 
negativa y su influencia en el campo de la educación. La segunda abordará el concepto desde una perspectiva más filosófica, la cual vendrá a considerar el aburrimiento de manera positiva y a relacionarlo directamente con la formación de la auténtica subjetividad humana. Finalmente, la tercera parte analizará nuestra sociedad del conocimiento actual, tratando de justificar por qué, hoy en día, saber aburrirse deviene, en el mundo que habitamos, competencia básica fundamental.

\section{El ABURRIMIENTO NEGATIVO: PSICOLOGÍA Y EDUCACIÓN}

Hacia los años 70 del siglo xx, afirmaba el psiquiatra Haskell E. Bernstein estar sorprendido ante el hecho de que «en medio de una riqueza sin precedentes, una libertad personal por igual, y una tecnología que [llenaba] nuestro tiempo a rebosar de avances e innovaciones emocionantes, a veces aterradoras, el aburrimiento se [hubiese] convertido en un serio obstáculo en la búsqueda de la felicidad para muchas vidas " $^{1}$ (Bernstein, 1975, 512). Resultaba sin duda extraño comprobar cómo mucha gente se aburría, cuando tantas posibilidades de entretenimiento había. Era como si nada pudiese llenarles; nada les satisfacía, todo parecía sobrarles.

Con el fin de dar respuesta a esta aparente paradoja, Bernstein distinguió entre dos tipos de aburrimiento, cuya confusión, según él, habría sido la causante de aquélla. Por un lado, nos encontraríamos con lo que él denominaba aburrimiento como respuesta ${ }^{2}$, el cual apuntaba a la sensación de pesar e insatisfacción que todo individuo podía experimentar ante determinados estímulos que, por una u otra razón, no le llenaban. Por otro lado, tendríamos el aburrimiento crónico, que, más que una sensación, sería un estado. Se trataría del estado de apatía, desgana y dejadez que muchas personas experimentaban independientemente de los estímulos que recibiesen. De esta forma, el motivo principal del aburrimiento no sería en este caso externo al sujeto, como sucedía en el primer tipo, sino más bien interno. Según Berstein, era este segundo tipo el «que recientemente [habría] crecido en número [de afectados] de manera significante» (ibíd., 515), siendo esto para él lo verdaderamente preocupante, pues mientras que el primero no constituía enfermedad mental alguna, el segundo sí; era patológico, ocasionaba malestar general (malaise) en quien lo vivía y, por tanto, era más difícil de paliar.

1. La traducción de todas las citas literales cuya referencia esté en un idioma distinto al castellano, como es el caso, ha sido realizada por el autor de este artículo.

2. En el original inglés, responsive boredom. Lo traducimos aquí por aburrimiento como respuesta, siguiendo la tradición en castellano de traducir la pareja stimulus-response - de la cual deriva el calificativo de responsive en este tipo de aburrimiento-, por estímulo-respuesta. No obstante, hemos de matizar que el concepto response tiene un sentido de reacción inmediata que el término respuesta no incluye. Este tipo de aburrimiento, por tanto, podría también haber sido traducido por aburrimiento como reacción, sin embargo, toda reacción implica una acción que, en este caso, sería una no acción, de manera que traducirlo así podría llevar a confusión. Es por esta razón que hemos tomado la decisión de tomar partido por la primera opción. 
Al no encontrar el aburrimiento como respuesta su causa en el interior del sujeto, éste conservaba sus funciones psicológicas intactas. De hecho, era capaz de sentir, al mismo tiempo que pesadumbre, cierta agitación que le llevaba a buscar alternativas con el fin de superarla. Por el contrario, la apatía generalizada que definía el aburrimiento crónico impedía cualquier voluntad de acción. "Siempre que la agitación predomine -decía Bernstein- la lucha por alcanzar la capacidad de sentimiento continúa” (ibíd., 518). El problema surgía cuando aquélla no existía. Efectivamente, uno podía aburrirse de un libro, una película, el gimnasio o lo que en ese momento un amigo le estuviese contando. En estos casos, bastaba con cambiar de actividad para evitar el peso del tiempo. Sin embargo, si era su vida entera la que le aburría; si no había actividad, objeto ni lugar que despertase su interés, modificar el contexto carecía de sentido. Era este individuo particular el que debía modificarse a y en sí mismo, ya que el problema no radicaba en los estímulos externos recibidos, sino en su "experiencia de no estar enteramente en contacto consigo mismo, de estar apartado de un aspecto esencial de su propia existencia» (ibíd., 517). De esta forma, se resolvía la paradoja, que terminaba por no serlo. Era posible aburrirse de ser y eso era independiente de que existiesen múltiples modos en los que el individuo se pudiese entretener.

Berstein, en tanto que psicoanalista, vería la causa del aumento de casos de aburrimiento crónico en determinados problemas generalizados durante la infancia del sujeto contemporáneo. Según él, estos problemas creaban traumas y éstos, a su vez, únicamente con terapia psicoanalítica podían ser después superados ( $i b i d$., 533 y ss.). Si bien antes de Berstein el estudio académico del aburrimiento en psicología había sido marginal, a partir de él no dejan de sucederse trabajos en torno al asunto (Smith, 1981); tanto fue así, que durante la década de los 90 ya podemos encontrar numerosas aproximaciones científicas y diversas maneras de medirlo y abordarlo (Vodanovich, 2003). Ahora bien, la paulatina pérdida de influencia del psicoanálisis dentro del discurso académico e investigador en psicología frente a perspectivas de carácter más cognitivo y conductual haría que la distinción de dos tipos aportada por Berstein dejase de estar tan clara, pues era imposible, según el discurso psicológico dominante del momento, separar de manera tajante el estado interior del individuo y la realidad externa que le rodeaba. Esto ha determinado que, aproximadamente a partir los años 90 del siglo pasado, "los métodos tradicionales de lidiar con el aburrimiento se [hayan] centrado en el incremento de la estimulación y elección [por parte del individuo] dentro de su contexto» (Martin, Sadlor y Stew, 2006, 193), dejando de lado terapias que atendían más al pasado del sujeto y a la manera que éste tenía de vivir con ello.

Esto no quiere decir que la terapia haya dejado de considerarse esencial, sobre todo en determinadas circunstancias. Simplemente se asume que el trabajo no puede ser meramente interno y que la modificación del contexto debe siempre acompañar al proceso. Es por eso que, para poder superar el aburrimiento, se exige la colaboración de otros expertos, sobre todo en ámbitos tan importantes dentro de la vida humana como son el trabajo, y antes, la escuela. Así pues, en tanto que 
base fundamental de todos los procesos educativos (Castejón et al., 2010), desde el punto de vista de la psicología de la educación, «en contraste con la psicología [pura], el aburrimiento tiende a ser atribuido a características propias de la escolaridad, esto es, a factores externos al estudiante» (Belton y Priyadharshini, 2007, 582) en cuyo mantenimiento o modificación, el docente y el equipo directivo tienen un papel esencial.

La definición de aburrimiento en tanto que «estado afectivo compuesto por sentimientos insatisfactorios, falta de estimulación y baja activación psicológica” (Pekrun et al., 2010, 532) es hoy en día ampliamente aceptada y reconocida en psicología. A su vez, numerosos estudios han demostrado que dicha carencia de estímulos durante la infancia y la adolescencia es causa fundamental de problemas tan importantes como el fracaso escolar (Wegner et al., 2008), el desarrollo de cuadros depresivos (Cosgrave et al., 2000), la drogadicción (Willging, Quintero y Lilliott, 2014), la delincuencia (Spaeth et al., 2015) e incluso la aparición de desórdenes alimenticios (Crockett, Myhre y Rokke, 2015). La escuela no puede quedarse atrás en la lucha contra estos problemas, siendo por ello que desde hace años viene modificando sus prácticas, con el fin de que el aburrimiento deje de estar presente en las aulas (Vogel-Walcutt et al., 2012). "La arquitectura estéril, la dirección burocrática, la superficial enseñanza para el examen, espacios vacíos que silencian toda expresión singular, todo contribuye a este fenómeno" (Gary, 2013, 427) y todo esto es lo que aparentemente hay que cambiar. La gente es más feliz cuando está ocupada, sobre todo, cuando se ocupa en algo que realmente le interesa (Hsee, Yang y Wang, 2010). El aburrimiento, por tanto, no deja de ser un obstáculo, debiendo sin duda alguna ser erradicado.

Desde principios de la década de los 2000, la evolución de las tecnologías de la información y la comunicación (TIC), así como su aplicación en las aulas, ha supuesto en este sentido toda una revolución (Marques y Majó, 2002). Las posibilidades que éstas ofrecen son infinitas y los estímulos a través de ellas no dejan de ser incrementados (Faizi, El Afia y Raddouane, 2013). La generación red aprende diferente (Tapscott, 2009), disponen de cantidades inabarcables de información a un solo clic, son capaces de atender a varias cosas a la vez y están acostumbrados a investigar por su cuenta (Hernández, Jomes y González, 2011). Nada tienen que ver con sus padres y abuelos, ahora denominados inmigrantes digitales (Prensky, 2001), cuyo mundo aún era apto para soportar la mera explicación del profesor. Ya no pueden, no saben, el tedio les consume, haciéndose imprescindible una escuela dinámica e innovadora que se adapte a las nuevas necesidades. Las Tic hacen posible esta escuela y es la esperanza de muchos docentes que éstas consigan que el mundo escolar sea tan poco aburrido como lo es el de fuera.

\section{El ABURRIMIENTO POSITIVO: FILOSOFÍA Y EDUCACIÓN}

Si bien, desde un punto de vista psicológico, el aburrimiento ha sido tradicionalmente considerado una experiencia sumamente negativa, podemos encontrar, 
tal y como hemos apuntado más arriba, desde una perspectiva más filosófica, planteamientos que le confieren el estatus de experiencia humana fundamental. Ahora bien, aunque la reflexión filosófica en torno a esta afección es casi tan antigua como la disciplina misma, su consideración positiva no lo es tanto. Realizaremos a continuación un breve recorrido histórico con el fin de explicar cuándo, cómo y por qué surgieron estos planteamientos. Finalmente abordaremos más en detalle el que posiblemente sea el más completo análisis jamás realizado del aburrimiento desde un punto de vista filosófico y adaptado a nuestro tiempo.

Los primeros planteamientos filosóficos en torno esta afección, en tanto que sentimiento de vacío, pesar, indiferencia y desgana, fueron siempre negativos, haciendo honor al origen etimológico del concepto, abborrēre -tener aversión, rechazo de o ante algo-, que de forma casual -o no tanto- hasta el siglo XVI no sería considerado como opuesto al de diversión (Corominas y Pascual, 1991). De hecho, no es el aborrecimiento sino la acedia, el sentimiento o afección que ha sido tradicionalmente señalado como antecedente directo de lo que hoy en día podríamos incluir bajo el concepto de aburrimiento (Giannini, 1987, 112 y ss.).

El término castellano acedia, del latín acid̆a, proviene a su vez del griego $\dot{\alpha} \kappa \eta \delta i ́ \alpha$, conformado por la partícula privativa $\alpha$ - y el verbo $\kappa \tilde{\eta} \delta$ os. Este último podría ser traducido por cuidado o preocupación y era comúnmente usado en la Antigua Grecia para referir la preocupación que el pueblo griego tenía por sus muertos y todo lo relacionado con ello -sacrificio, honores, duelo, etc.-. Quien no ponía cuidado en el cumplimiento de todos los rituales que debían acompañar a la

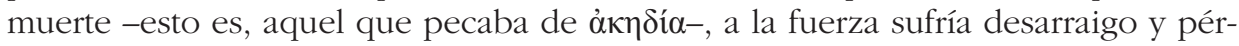
dida de identidad (Peretó Rivas, 2011). En la Antigüedad, comunidad e individuo eran inseparables, de modo que no cumplir con los usos y costumbres suponía

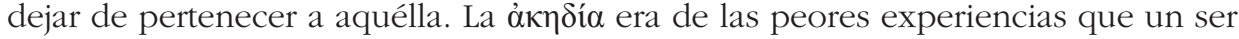
humano podía vivir, pues de ser alguien en tanto que miembro de algo, pasaba a convertirse en nadie, invisible no solamente a los ojos de los demás, sino también a los suyos propios.

El cristianismo heredó el concepto, pasando a ser una constante su presencia dentro del ámbito del pensamiento medieval (Forthomme, 2000). Para Tomás de Aquino, uno de los mayores exponentes filosóficos de este periodo y quizá el que mayor número de páginas dedicó al asunto, la acedia era un pecado mortal. La despreocupación espiritual que acarreaba su padecimiento conllevaba inevitablemente un profundo alejamiento de Dios, de manera que también constituía uno de los peores males que el ser humano podía llegar a experimentar. El problema aquí no era tanto el distanciamiento de la comunidad como de Dios, ya que uno podía cumplir con los preceptos cristianos y descuidar al mismo tiempo su relación con Dios. Así pues, mientras que los griegos consideraban esta afección en tanto que negligencia, los medievales pasaron a entenderla más bien como un tipo de tristeza -posiblemente el más doloroso de todos- (Echeverría, 2004). De hecho, el mismo Tomás de Aquino lo definiría como tristitia saeculi (De Aquino, 2001, q11 a3), que con el tiempo se derivaría en la expresión francesa mal du 
siècle, ideada por Chateaubriand para referir la melancolía o tedio moderno (Sánchez-Megía, 1996).

Tal y como señala Svendsen $(2006,64)$, «mientras que la melancolía es un concepto ambiguo que abarca tanto enfermedad como sabiduría, la acedia permanece como concepto puramente negativo»; o, lo que es igual, en tanto que dolencia o enfermedad. No habría podido ser de otra forma, pues si a algo condena el aburrimiento es a la soledad. Cuando uno está aburrido, se siente abandonado por aquello que debía en esos instantes ocupar su atención. Se encuentra inevitablemente solo, incomprendido y apartado de lo que en ese momento está pasando; lo cual, para alguien educado en la necesidad de sentirse siempre acompañado, puede llegar a resultar la peor de las sensaciones. Así pues, el problema de antiguos y medievales no sería tanto el alejamiento de la comunidad o de Dios, sino más bien la consecuencia directa que esto tenía; a saber, el enfrentamiento a una absoluta soledad para la que no estaban preparados. El tedio o aburrimiento, sostiene Svendsen (ibid., 40), "presupone la subjetividad o, lo que es lo mismo, la conciencia de uno mismo"; y el ser humano en Occidente no se encontrará preparado para hacerse cargo de ella hasta la Modernidad, cuando la noción de sujeto separado e independiente de cualesquiera otras entidades permita al individuo permanecer solo consigo mismo sin por ello sentir un insoportable pesar.

A partir de los siglos XVI y XVII en adelante, el papel del individuo en su particularidad será cada vez más esencial, de manera que podemos encontrar varios autores destacados remarcando el valor del aburrimiento o tedio como base para la construcción de la auténtica subjetividad. Evidentemente, sólo cuando uno se aburre -esto es, únicamente cuando uno rechaza todo lo que le rodea sin reparos- puede realmente enfrentarse a sí mismo, pues nada más que a sí mismo encontrará en su soledad. Así, por ejemplo, Pascal, para quien el aburrimiento será elemento esencial de la condición humana (Pascal, 1998, 44), afirmaba que «si el hombre fuera feliz, lo sería en cuanto menos divertido, como los santos y Dios. Sí -continuaba el autor-, ¿pero no es ser feliz sentirse alegre con la diversión? -No -respondía-, porque viene de otra parte y de afuera; y así es dependiente, y en todo momento sujeto a ser turbado por mil accidentes, que hacen inevitables sus aflicciones» (ibid., 78). Quien no se aburría nunca simplemente se dejaba llevar y esto iba en contra de la total libertad del sujeto en su individualidad.

Tras él vendrían otros muchos pensadores reclamando, en la misma línea, la necesidad humana de aburrimiento y tiempo libre o de ocio como conditio sine qua non para poder experimentarlo. Sobre todo en el Romanticismo, que como reacción al pensamiento ilustrado igualador en lo público y a una ética protestante que concedía a la actividad y al trabajo un valor esencial, reivindicaron la formación del sujeto en la vida privada, donde nadie, en principio, lo podría homogeneizar ${ }^{3}$. De esta forma, Kierkegaard $(2006,296)$ mantendrá que «quien no tiene

3. No entraremos aquí en el análisis del pensamiento ilustrado y la religión protestante en contraposición con el pensamiento romántico. Baste decir que el pensamiento ilustrado se centró en 
sentido de la ociosidad muestra con ello que no ha alcanzado lo humano"; para Schopenhauer (2009, 303 y ss.), el aburrimiento será, igual que lo había sido para Pascal, condición esencial de nuestra naturaleza; y Nietzsche, de quien puede decirse que de algún modo intuyó la importancia de una pedagogía de la soledad (Lemos Brito, 2012), sostendrá que «el aburrimiento es la calma chicha del alma que precede a los alegres vientos y a la feliz carrera; hay que soportarlo y esperar su efecto. [...] Disipar el aburrimiento de cualquier manera -concluirá el autor- es lo vulgar" (Nietzsche, 2003, 68).

Ahora bien, a pesar de que estos autores revindicaban lo que, según su sistema de pensamiento, intuían como verdadero, ninguno realizó un análisis exhaustivo del aburrimiento. Habrá que esperar al siglo xx y al filósofo alemán Martin Heidegger, para que éste por fin sea hecho. Heidegger (2007) distingue tres tipos de aburrimiento a los que denominará aburrirse por, aburrirse en y uno se aburre, remarcando el carácter impersonal de esta tercera forma. Aunque los tres se encuentran divididos en función de su mayor o menor profundidad, están relacionados entre sí al poder ser analizados en función de dos categorías clave. "Lo que aburre -dirá Heidegger-, lo aburrido es lo que da largas y sin embargo deja vacío» (ibid., 121).

El primero de los tipos, considerado por este autor como el más superficial de todos, es el que con mayor frecuencia todos experimentamos. Cuando nos aburrimos por algo, tenemos una clara idea de lo que nos aburre, podemos señalarlo e incluso podríamos aventurarnos a apuntar sin equivocarnos los motivos que nos llevan a calificarlo de aburrido. Heidegger pone como ejemplo tener que esperar varias horas en la estación hasta que salga nuestro tren. Por mucho que tratemos de dedicarlo a otras actividades, el tiempo en estas circunstancias pasa lento, parece no avanzar. Queremos llegar a nuestro destino cuanto antes y no podemos evitar pensar compulsivamente en ello. Estamos convencidos de tener mejores cosas que hacer, lo cual en estas circunstancias consideramos un hecho. El tiempo que creemos no tener nos da largas y esto nos llega a desesperar, no estamos como para perderlo. A su vez, no solamente es eso lo que ocurre, sino que, aparte, solemos

el espacio público, en la abolición de privilegios y en el papel del individuo particular en tanto que ciudadano (DíAz, 1994). Este pensamiento, unido a la extensión de la religión protestante que dio lugar al capitalismo y al sistema de producción de la fábrica (WEBER, 1998), hizo que se estableciese un ideal de dignificación de la actividad y del trabajo que hacía del aburrimiento un obstáculo. Así lo entiende Kant, por ejemplo, cuando afirma que «el hombre tiene que mantener su vitalidad haciendo muchas cosas. El valor del hombre -según este filósofo- estriba en la cantidad de cosas que hace. La ociosidad supone -consecuentemente- una degradación de la vida» (KANT, 1988, 201). De hecho, serán las mujeres de las clases adineradas las que en mayor medida lo experimenten e, inmersas en un sistema social que lo condenaba, nunca lo vivieron de forma positiva, sino como una enfermedad que las atormentaba (De Martino y Bruzzese, 1996: 203 y ss.). Habrá que esperar al siglo Xix, cuando la reflexión y el pensamiento empiecen a primar sobre la actividad y el beneficio económico. Será ésta la época en la que una visión más positiva del aburrimiento sea recuperada. A este respecto, véase Gras BALAGUER (1988). 
sentir cierta sensación de vaciamiento. "Dejar vacíos o estar colmados ${ }^{4}$-dice Heidegger- concierne al trato con las cosas. El dejarnos vacíos se ha eliminado cuando las cosas están a disposición, presentes» (ibíd., 133); es decir, cuando cada cosa nos da lo que de ella esperamos en cada momento. Si el tren, del cual esperamos que nos lleve cuanto antes a un destino determinado, tarda en salir, nos está fallando y esto nos hace sentir irremediablemente vacíos, a falta de algo.

El segundo tipo es un poco más profundo, aunque también prácticamente todos, al menos en alguna ocasión, lo hemos experimentado. Cuando nos aburrimos en algo, estamos aburriéndonos en una situación que debería ser cualquier cosa menos aburrida. Heidegger pone el ejemplo de una fiesta. Hemos quedado con amigos para pasar una agradable velada y todo va bien. Hay buena comida, la gente es simpática, incluso la conversación es interesante, pero, aun así, nos estamos aburriendo. Aquí nos es más complicado señalar el motivo de nuestro aburrimiento. Parece difícil, a su vez, analizarlo en función de las categorías del dar largas y del dejar vacios, pues no es que tengamos otra cosa mejor que hacer -de hecho, hemos reservado tiempo para ir a la fiesta- y nos encontramos ahí, inmersos en lo que está pasando, luego, en principio, vacíos tampoco estamos. No obstante, según este autor, no es que estas categorías hayan dejado de ser aplicables, lo que ocurre es que son más profundas.

En estas ocasiones, la situación -en este caso la fiesta- lo llena todo, nos dejamos arrastrar por lo que sucede sin estar del todo presentes, aunque tampoco ausentes. Según Heidegger, «el ser dejados vacíos no sucede sólo en y a causa de la falta de lo que llene, de que este o aquel ente se nos deniegue, porque su propio presupuesto, la búsqueda de un ser llenado por lo ente, en esta dejadez ya está impedida" (ibíd., 155-156). Nosotros mismos nos desvanecemos en el fluir del momento y, por tanto, no hay nada que llenar; «este vacío es el dejarnos atrás nuestro auténtico sí mismo" (ibíd., 158). En cuanto al dar largas, también se produce pues, aunque dispongamos de tiempo, este tiempo que se muestra y que parece que no discurre, está detenido. Ahora bien, «eso no significa en absoluto que haya desaparecido, sino que este estar detenido del tiempo es el dar largas más original y eso significa oprimin (ibid., 161). Oprime precisamente por no discurrir, por no permitirnos que pasemos por él, sino que nos posiciona de tal manera que él pasa por nosotros sin que apenas percibamos su discurrir. "En el primer caso lo que aburre viene en cierto modo de fuera, somos aburridos por... Una situación determinada con sus circunstancias nos instala en el aburrimiento. Aquí, por el contrario, en el segundo caso, lo que aburre no viene de fuera: se alza desde la propia existencia» (ibíd., 167); debido a ello es más profundo y oprime más. Todo es pasatiempo y, al mismo tiempo, todo es aburrimiento.

El tercer tipo será el que cambie la perspectiva de los dos primeros, pues será el que aparezca como realmente positivo y aquéllos, si conseguimos soportarlos,

4. La cursiva es del autor. Siempre que a lo largo del artículo aparezca letra cursiva en alguna de las citas literales pertenecerá a su autor a menos que explícitamente se indique lo contrario. 
podrán conducirnos a él. «El aburrimiento profundo -continua Heidegger- aburre cuando decimos, o mejor, cuando, callando, sabemos que es ist einem langweilig [uno se aburre]» (ibíd., 176), atendiendo a lo impersonal de la oración. Aquí ya no habrá ejemplo, ya que no hay una situación particular en la que se produzca y no será tampoco fácil de entender, al ser muy pocas personas las que realmente lo experimentan. En él se producirá lo que este autor denomina «una comprensión excepcional» (ibid., 178). En contraposición con los ejemplos anteriores, aquí nos veremos forzados a escuchar, a estar atentos, a pesar de que la indiferencia siga definiendo nuestro modo de estar. De hecho, se ve aquí ampliada al máximo, puesto que «nos encontramos de algún modo abandonados, no sólo no ocupados con este o aquel ente, no sólo detenidos por nosotros mismos en este o aquel aspecto, sino en su conjunto» (ibíd., 182).

Se tratará, por lo tanto, de un dejarnos vacíos que todo lo ocupará, pues todo se verá denegado, incluso nosotros mismos. Con total incapacidad para actuar, indiferentes a todo lo existente, nos abriremos, sin embargo, al mundo de lo posible. Nuevas posibilidades se abren en nuestra mente porque ninguna aparece refrenada. Toda la creatividad se pone en marcha, nada hay que la detenga porque nada importa en estos momentos. No obstante, es en ellos donde podemos descubrir lo verdaderamente importante. Así, siguiendo a Heidegger, "este empobrecimiento peculiar que con este es ist einem langweilig se opera en relación a nuestra persona trae al mismo tiempo por primera vez, en toda su desnudez, a él mismo en tanto que el sí mismo que es ahí y que ha asumido su ser-ahí» (ibíd., 186). Sólo aquí, vaciados de todos y de todo podemos llegar a descubrir quién realmente somos. Desde cero nos reconstruimos y desde cero nos hacemos conscientes de que somos alguien en el mundo, diferentes del resto. Arrojado a un mundo previamente ordenado por otros, en el uno se aburre, el sujeto, desprovisto de cualquier condición impuesta, en soledad se enfrenta a su mundo, a él mismo y a lo posible, que deja de encontrarse configurado meramente por lo dado. «El [ser humano] -dice Agamben comentando a Heidegger- es sencillamente un animal que ha aprendido a aburrirse, se ha despertado del propio aturdimiento y al propio aturdimiento. Este despertarse del viviente al propio ser aturdido, este abrirse, angustioso y decidido, a un no-abierto, es lo humano" (Agamben, 2005, 91). Únicamente desde la indeterminación consigue el sujeto alcanzar su auténtica determinación particular. Este proceso de determinación, desde inicios de la Modernidad, constituye lo humano y, desde un punto de vista educativo, es lo que desde hace años luchamos por preservar.

Heidegger termina su análisis del aburrimiento haciendo un guiño a una clase de pedagogía que hoy es dominante y que ya entonces, hacia los años 50 del siglo pasado, se estaba imponiendo. Afirmaba Heidegger que "ya sólo nos esforzamos por destrezas adquiribles. Todo está lleno de problemas y preguntas de la pedagogía. Pero la fuerza y el poder -concluía- nunca pueden reemplazarse por un acumulamiento de destrezas, sino que, si hay algo que se alcanza con esto, es sólo el asfixiamiento de todo eso» (Heidegger, 2007, 210). Trataremos en el siguiente 
apartado de explicar qué quiere decir esto pues, quizá, en el mundo educativo de las destrezas y las competencias hayamos infravalorado y malentendido el significado profundo del aburrimiento.

\section{EL ABURRIMIENTO COMO COMPETENCIA: SOCIEDAD DEL CONOCIMIENTO Y EDUCACIÓN}

En su novela La identidad el escritor Milan Kundera introduce de manera aparentemente superficial, por medio de uno de sus personajes protagonistas, una teoría del aburrimiento. Existen «tres tipos de aburrimiento -afirma este personaje-: el aburrimiento pasivo: la chica baila y bosteza; el aburrimiento activo: los aficionados a las cometas; y el aburrimiento rebelde: la juventud que quema coches y rompe escaparates» (Kundera, 2012, 23). Los dos primeros tipos recuerdan claramente a los analizados por Heidegger. No obstante, el tercero difiere. Este tercer tipo es en el que, tal y como veíamos anteriormente, se centra la psicología. No obstante, el filósofo alemán parece no tenerlo en cuenta en tanto que forma de aburrimiento. Podríamos pensar que ha pasado para él desapercibido y que el motivo de no incluirlo es debido al despiste o al olvido. Ahora bien, resultaría extraño en un análisis tan exhaustivo. Otra razón, quizá más plausible, es que éste, en realidad, no sea un tipo de aburrimiento.

El aburrimiento es un estado pacífico en el que el individuo se encuentra en proceso de vaciamiento y en el que el tiempo le da largas, no parece discurrir. Su consecuencia inmediata es la inacción, no la acción y mucho menos violenta. Este, considerado por muchos, tipo de aburrimiento es el que en los últimos años no ha dejado de crecer, hasta el punto de que algunos lo han llegado a calificar de epidemia de la Modernidad (Spacks, 1995). Sin embargo, ya lo apuntábamos más arriba, es complicado pensar en este incremento dentro de un mundo en que tantas cosas hay por y para entretenerse; y es que, quizá, el problema no sea el vaciamiento, sino todo lo contrario, la completitud. Tal y como afirma Corea (2004, 50), «[en nuestro mundo] todo huele, todo brilla, todo significa. Nuestras prácticas cotidianas están saturadas de estímulos, entonces, la desatención o la desconexión son los modos de relación con esas prácticas o esos discursos sobre-saturados». Necesitamos parar y la mente nos pide descanso. Sin embargo, no siempre se puede. A su vez, nuestro cansancio puede ser interpretado como inadecuación de estímulos, presentándosenos nuevos. En estos instantes seguimos acumulando más y más información llena de significado. No obstante, el problema de cuando todo significa, es que nada acaba significando. De esta forma, terminamos llenos de nada y cuando ya no aguantamos más explotamos. Si somos adultos, reprimiremos nuestro hartazgo y desarrollaremos depresión, estrés, ansiedad o algún otro tipo de enfermedad mental. Si, en cambio, somos adolescentes, aún con poco control sobre nosotros mismos, es posible que rompamos escaparates, quememos coches o nos dediquemos de manera compulsiva a comer. Nuestros jóvenes no se encuentran vacíos, no están aburridos, sino que se encuentran llenos de nada, fatigados de tanta nada en un mundo que no les permite parar. 
Hoy en día, desde que el niño nace, todos los juegos a los que dedique su tiempo han de ser educativos ${ }^{5}$. Luego entrará en el colegio, con el fin de adquirir toda una serie de conocimientos, destrezas y actitudes que se consideran necesarias para en un futuro incorporarse de la forma más completa posible al mundo adulto. Pero esto no será suficiente, pues vivimos en un mundo líquido y cambiante (Bauman, 2002) que exige múltiples competencias con el fin de poder ser flexibles a cualquier situación. Debido a ello, habrá que reservar las tardes para aprender idiomas, tocar algún instrumento y hacer deporte, pues el cuerpo merece también ser cuidado. Empezará aquí un proceso de lifelong learning que ya nunca cesará, ya que «la educación [en casa] y en la escuela no es [ya] condición suficiente para una vida adulta, autónoma» (Simons y Masschelein, 2008, 398), siempre es necesario más.

Ni siquiera la vida universitaria, que antaño estuviera separada del ámbito de lo social con el fin de dedicarse al estudio, a la investigación y al conocimiento sin más, se ha salvado de entrar en la dinámica de la productividad. Actualmente el discurso del publish or perish rige la vida académica (Smeyers et al., 2014), coleccionamos certificados de igual modo que nuestros jóvenes coleccionan amigos en la Red; no se imparten disciplinas sino créditos cuyos contenidos, año tras año, no tienen por qué corresponderse; y los docentes, por su parte, no pueden permitirse un parón de varios años con el fin de dedicarse meramente al estudio y a la indagación. La consecuencia de todo esto es que los académicos ya no estudian, se encuentran exhaustos, fatigados (D’Hoest y Lewis, 2014), tanto o más que sus alumnos, que desde la cuna ya vienen estándolo.

La denominada sociedad del conocimiento que habitamos ha permitido que ya no sólo sean unos pocos los que manejen la información, ahora todos podemos ayudar a construirla gracias a las TIC y a la web 2.0 (O'Reilly, 2005). Cierto es que a nivel de formación en participación social y ciudadana -siempre y cuando se sigan los criterios pedagógicos adecuados-, esto supone toda una revolución en sentido positivo (García del Dujo, Muñoz Rodríguez y Hernández Serrano, 2015). Ahora la voz de todos puede ser fácilmente escuchada y se han agilizado y ampliado las formas de colaboración. No obstante, esto también ha hecho que seamos cada vez más demandados, que haya más cosas que saber y a las que atender. Tenemos que ser competitivos y eficaces, no sólo en nuestra vida académica y profesional, sino también en la personal. Quien no esté al día de todo se encuentra perdido, retrasado. Igual que le ocurría al destinatario de la sociedad de la información, pero a un nivel mucho mayor, el individuo de la sociedad del conocimiento se halla saturado, "todas las imágenes se refieren a él, le invocan, le nombran y le solicitan. Y, como ocurre con esas estatuas sagradas que los peregrinos acarician en ciertas iglesias desde hace siglos, cada nuevo touch degrada un poco más el

5. Muy a pesar de que no siempre sea cierto ni venga avalado por ningún estudio. El adjetivo "educativo" ha terminado convirtiéndose en estrategia de marketing. A este respecto véase SiLvA, GONÇALVES Y FERREIRA (2014). 
monumento, y cuando todo el mundo lo haya fotografiado, ya no quedará de él más que una imagen. Habrá dejado de existir por exceso de actos de referencia» (Pardo, 1989, 176).

Cada vez es más complicado ser uno mismo cuando no hay tiempo apenas para responder a lo que a uno le llega del mundo exterior. Antes de llegar al aula, un estudiante ya ha visto varios carteles publicitarios, se ha metido en sus redes sociales favoritas, ha comentado fotos, videos y respondido a varios mensajes instantáneos. Dentro de la escuela, le esperan seis horas de más estímulos a través de los cuales el docente tratará cumplir con un currículo previamente medido y estipulado hasta el más mínimo detalle. Tal y como afirma Bárcena $(2014,50)$, «[se da por hecho que] una buena enseñanza tiene como resultado, previsto y previsible, el aprender en el otro, sin dejar tiempo para ninguna clase de despertar en el estudiante", cuando es precisamente ese tiempo de espera, libre para pensar, el que puede realmente producir un aprendizaje verdaderamente interiorizado.

No es casual que precisamente hacia los años 70 del siglo Xx, cuando comenzaron a extenderse las teorías del capital humano y la influencia del campo de la economía en educación (Shultz, 1971; Becker, 1964), se empezase a prestar al mismo tiempo especial atención al aburrimiento desde la perspectiva de la psicología de la educación. Desde entonces se ha confundido aburrimiento con fatiga y, precisamente cuando aquél podía producirse si se dejaba a la mente descansar, se ha optado por enviar más estímulos, por miedo a que la pereza pudiese llegar (Hauser, 2015). El aburrimiento se ha entendido como un obstáculo a todos los niveles, tanto así, que hay autores que defienden que incluso debe ser mermado dentro del tiempo libre o de ocio (Ragheb, 2002), el cual, por derecho propio, tradicionalmente le había pertenecido.

Decía la pensadora Hannah Arendt $(1984,216)$ que "quizá nada indique más claramente que el hombre existe esencialmente en la dimensión plural que el que su soledad [solitude] se actualice, durante la actividad pensante». Cada individuo humano es diferente, único e insustituible, pero necesita tiempo libre para hacerse consciente de ello. Se trata de tiempo para pensar, para ordenar sus ideas, para reflexionar en torno a lo mucho que, día tras día, le llega del exterior. De lo contrario, terminaría siguiendo el camino marcado, dejando que pase el tiempo, pero sin permitir que deje huella en él. Este tiempo libre, si es realmente libre -es decir, liberado de toda ocupación-, ha de ser a la fuerza tiempo de aburrimiento.

Ya en los años 30 del siglo pasado, sostenía Bertrand Russell (2003, 38-39) que «nos aburrimos menos que nuestros antepasados, pero tenemos más miedo a aburrirnos». El contexto socioeconómico en el que vivimos nos ha transmitido eso, cuando, en verdad, es el tiempo del aburrimiento el que fomenta la adquisición de una auténtica subjetividad personal, fomentando capacidades educativas esenciales como la creatividad. Efectivamente, «quien se aburra al caminar y no tolere el hastío deambulará inquieto y agitado, o andará de una a otra actividad. Pero, en cambio, quien posea una mayor tolerancia al aburrimiento reconocerá, después de un rato, que quizás andar, como tal, lo aburre. De este modo, se animará a inventar 
un movimiento totalmente nuevo» (Han, 2012, 36). Esta invención no vendrá de fuera, no habrá sido exigida ni demandada, sino que partirá de un sí mismo, que en su tiempo de aburrimiento habrá conocido aquello que de manera autónoma le permite avanzar. Y es que «quizás sea el momento de recuperar el sentido perdido del tiempo libre. Quizás necesitemos parar de pensar en la ausencia de distracción externa como aburrimiento posible y comenzar a ver en él una oportunidad de proveer un espacio para la creatividad de nuestros niños» (Kirova, 2004, 263).

El mayor problema que tenemos hoy en día, en relación con nuestro pasado más inmediato, es que antes de la llegada de las Tic, a pesar del miedo y la desesperación, aún las personas, aunque fuese por casualidad, en algún momento tenían a la fuerza que lidiar con el aburrimiento. Actualmente esto se hace complicado, sobre todo desde que el mundo nos acompaña, vayamos donde vayamos, en nuestro bolsillo. La sociedad nos pide que seamos originales, creativos y autónomos; que tengamos una auténtica subjetividad personal ${ }^{6}$, pero luego pone trabas a los condicionantes que podrían llevarnos a ello. Cierto es que fuera de la escuela es complicado que un tiempo realmente libre se pueda dar. Siempre se puede pedir ayuda a los padres, pero la vida familiar está cada vez más influida por la social. Así pues, sólo la escuela, en tanto que paréntesis de la vida social, puede conseguir que las nuevas generaciones experimenten lo que difícilmente de otro modo podrían experimentar. Se trata de recuperar el ideal clásico de la escuela como $\sigma \chi 0 \lambda \eta ́$, como tiempo libre; "Como tiempo presente y como espacio intermedio, un lugar y un tiempo para las posibilidades y para la libertad" (Simons y Masschelein, 2014, 39).

Poder y saber aburrirse aparece hoy en día, por tanto, como competencia esencial. Uno debe saber lidiar con su aburrimiento con el fin de descubrir quién es él o ella en realidad. No se trata, sin embargo, de forzarlo, de hacer que las clases sean aburridas, pues «mientras que el aburrimiento en sí podría abrir posibilidades para nuevos compromisos, los intentos de hacer que alguien se aburra no lograrían este propósito" (Lewkowich, 2010, 63). Tampoco debemos prohibir ni alejar a las nuevas generaciones de las TIC, ya que son su mundo y desean con razón disfrutar de él; «la cultura infantil [y juvenil] es ante todo una pedagogía del placer y, como tal, no es posible ir en su contra simplemente autoexcluyéndonos y excluyendo a nuestros hijos de ella. Se deben formar estrategias de resistencia que entiendan la relación entre la pedagogía, la producción de conocimiento, la formación de la identidad y el deseo" (Steinberg y Kincheloe, 2000, 19). Estas estrategias han de conllevar momentos de acción y de movimiento, pero también de pausa, de espera y reflexión. Esto no nos garantiza que el aburrimiento llegue, y mucho menos el más profundo. Esta afección no es inducible ni transmisible de manera directa, sino que su aparición depende de cada persona en particular. No obstante, introducir estos tiempos y espacios de pausa y reflexión puede ayudar a que se produzca,

6. Numerosos estudios podrían citarse a este respecto, pero ya que muchos de ellos se basan en los informes realizados por la Organización de las Naciones Unidas a la hora de fundamentar sus posiciones, mencionamos aquí como ejemplo Delors (2013). 
pues son sin duda sus condiciones de posibilidad. Sólo de esta forma, a diferencia de lo que mantenía Jankélevitch, podrá el aburrimiento por fin convertirse en un asunto serio.

\section{CONCLUSIÓN}

En 1989 el poeta y ensayista de origen ruso Joseph Brodsky dio una conferencia en la ceremonia de graduación de ese curso en el Darmoth College. Bajo el título de Elogio del aburrimiento, quiso llamar la atención sobre un sentimiento que habría de ser común en sociedades donde un exceso de población haría que la ocupación comenzase a escasear. Rodeados de tecnologías que permitían grabarlo todo, que podían hacer por nosotros prácticamente todo, era normal que la redundancia del tiempo de manera generalizada se comenzase a sentir. Mucho que encender y apagar, demasiadas cosas que poner en marcha, que hacer y aprender, pero, en el fondo, nada realmente nuevo, nada propio, todo ajeno. Era debido a tanta cantidad de nada que, según él, muchas personas, por miedo a quedarse vacías, terminasen acudiendo a los psicotrópicos y a las drogas. Al menos así, durante algunos instantes podían sentirse alguien (Brodsky, 1997, 104 y ss.).

Con esto quería él que los estudiantes viesen que comprendía su situación. Sin embargo, pretendía al mismo tiempo mostrarles que aquélla no era la mejor opción. De este modo, les recomendaba que "cuando [fueran] golpeados por el aburrimiento, [fuesen] a por él; [que dejasen] que [les aplastase]; [que se sumergiesen], [que tocasen] fondo» (ibid., 108). No para que sufrieran, sino porque sabía que ésta era la única forma de que abriesen una "ventana en la infinitud del tiempo, es decir, en [su] insignificancia en ella" (idem). Esta insignificancia les haría tomar conciencia de su finitud, de su particularidad en una vida llena de seres diferentes. Para Brodsky "cuanto más finita es una cosa, más cargada está de vida, emociones, alegría, miedos, compasión» (ibíd., 111) y es precisamente eso lo que él quería para estos jóvenes; que se sintiesen ellos mismos, vivos y con conciencia de poder ser quienes ellos quisiesen ser.

Ya hace más de 25 años del discurso de Brodsky, sus palabras no parecen haber sido escuchadas y el mundo que él describía ha multiplicado sus excesos hasta la extenuación. En educación seguimos fomentando la huida del aburrimiento cuando, tal y como hemos visto, deberíamos fomentar las condiciones de posibilidad que faciliten su experimentación. Somos como la reina roja en la novela de Lewis Carroll $A$ través del espejo y lo que Alicia encontró allí, cogemos a nuestros jóvenes de la mano y los hacemos correr más y más rápido para que las cosas al final se queden como están (Carroll, 2013), cuando deberíamos educarles para que tomasen ejemplo de Momo, la protagonista de la novela de Michael Ende, que aprende que sólo yendo lentamente, e incluso a veces incluso caminando al revés, uno puede de y por sí mismo realmente aprender (Ende, 1994).

Este cambio educativo es lo que este artículo ha pretendido mostrar como necesario. No podemos confundir fatiga con aburrimiento, no debemos huir de él 
sin antes conocerlo. Mucho camino queda por delante a este respecto. Cierto es que se va avanzando y que ya desde el ámbito de la psicología empiezan a considerarse aquellos aspectos que tiene de positivo (Epidorou, 2014), también en el ámbito educativo e incluso en el del trabajo (Jackson y Carter, 2011), dentro del cual podemos encontrar autores que hasta tal punto lo defienden que han llegado a mostrar sus beneficios en la consecución de actitudes tan alejadas en principio de este sentimiento como puede ser la de liderazgo (Carroll, Parker e Inkson, 2010). El aburrimiento es una competencia, no de resultados inmediatos, eso es cierto, pero sin duda con resultados. Para que éstos se produzcan sólo necesitamos una cosa: tiempo.

\section{REFERENCIAS BIBLIOGRÁFICAS}

Agamben, G. (2005) Lo abierto. Valencia, Pre-Textos.

ARENDT, H. (1984) La vida del espiritu. Madrid, Centro de Estudios Constitucionales.

BÁrCena, F. (2014) Una educación proustiana. Pedagogía more litteratura demonstrata. Teoría de la Educación. Revista Interuniversitaria, 26 (2), 43-67.

Bauman, Z. (2002) Modernidad líquida. Madrid, Fondo de Cultura Económica.

Becker, G. S. (1964) Human Capital: A Theoretical and Empirical Analysis, with Special Reference to Education. Chicago, University of Chicago Press.

Belton, T. y PriYadharshini, E. (2007) Boredom and Schooling: a cross-disciplinar exploration. Cambridge Journal of Education, 37 (4), 579-595.

Bernstein, H. E. (1975) Boredom and the Ready-Made Life. Social Research, 42 (3), 512-537.

Brodsky, J. (1997) In Praise of Boredom, en On Grief and Reason. Nueva York, Farrar, Strauss and Giroux, 104-113.

CARROLL, L. (2013) Through the Looking Glass and What Alice Saw There. Londres, Forgotten Books.

Carroll, B. J.; Parker, P. e Inkson, K. (2010) Evasion of boredom: An unexpected spur to leadership? Human Relations, 63 (7), 1031-1049.

Castejón, J. L.; González, C.; Gilar, R. y Miñamo, P. (2010) Psicología de la Educación. San Vicente (Alicante), ECU.

Corea, C. (2004) Pedagogía y comunicación en la era del aburrimiento, en Corea, C. y LEWKowicz, I. Pedagogía del aburrido. Escuelas destituidas, familias perplejas. Buenos Aires, Paidós, 41-70.

Corominas, J. y Pascual, J. A. (1991) Diccionario crítico etimológico castellano e hispánico. Madrid, Gredos.

Cosgrave, E.; McGorry, P.; Allen, N. y Jackson, H. (2000) Depression in young people: a growing challenge for primary care. Australian Family Physician, 29, 123-127.

Crockett, A. C.; Myhre, S. K. y RokKe, P. D. (2015) Boredom proneness and emotion regulation predict emotional eating. Journal of Health Psychology, 20 (5), 670-680.

De Aquino, T. (2001) De Malo. Madrid, Consejo Superior de Investigaciones Científicas.

De Martino, G. y Bruzzese, M. (1996) Las filósofas. Madrid, Cátedra.

Delors, J. (2013) Los cuatro pilares de la educación. Galileo, 23, 103-110.

D'Hoest, F. y LeWIS, T. (2014) Exhausting the fatigue university: in search of a biopolitics of research. Ethics and Education, 10 (1), 49-60.

Díaz, F. (1994) Europa: De la Ilustración a la Revolución. Madrid, Alianza. 
ECHeverría, M. (2004) La acedia y el bien del hombre en Santo Tomás. E-Aquinas. Revista Electrónica Mensual del Instituto Universitario Virtual Santo Tomás, Época I, 2 (1), 13-34. Consultado el 17 de junio de 2016. http://www.e-aquinas.net/epoca1/ la-acidia-segun-santo-tomas/.

Ende, M. (1994) Momo. Madrid, Alfaguara.

EPIDOROU, A. (2014) The bright side of boredom. Frontiers in Psychology, 5 (1245). Consultado el 18 de junio de 2016. http://journal.frontiersin.org/article/10.3389/fpsyg.2014.01245/ full.

Faizi, R.; El Afia, A. y Raddouane, Ch. (2013) Exploring the Potential Benefits of Using Social Media in Education. International Journal of Educational Psychology, 3 (4), 50-53.

Forthomme, B. (2000) De l'acédie monastique à l'anxio-dépression. Histoire philosophique de la transformation d'un vice en pathologie. París, Synthélabo.

García del dujo, Á.; Muñoz Rodríguez, J. M. y Hernández Serrano, M. J. (2015) Medios de interacción social y procesos de (de-re)formación de ciudadanías. Teoría de la Educación. Revista Interuniversitaria, 27 (1), 85-101.

GARY, K. H. (2013) Boredom, Contemplation and Liberation. Philosophy of Education 2013, 427-435.

Giannini, H. (1987) La "reflexión» cotidiana. Santiago de Chile, Editorial Universitaria.

Gras Balaguer, M. (1988) El Romanticismo como espíritu de la modernidad. Barcelona, Montesinos Editor.

Han, B. C. (2012) La sociedad del cansancio. Barcelona, Herder.

Hauser, M. (2015) The Colonization and Decolonization of Time. Philosophy Study, 5 (6), 287-291.

HeIdegGer, M. (2007) Los conceptos fundamentales de la metafísica. Madrid, Alianza Editorial.

HERnÁNDEZ, M. J.; Jomes, B. y GonZÁLEZ, M. (2011) La generación Google. Evolución en las predisposiciones y comportamientos informativos de los sujetos. Pedagogía Social. Revista Interuniversitaria, 18, 41-56.

Hsee, C. K.; Yang, A. X. y Wang, L. (2010) Idleness Aversion and the Need for Justifiable Busyness. Psychological Science, 21 (7), 926-930.

JaCKSON, N. y CARTER, P. (2011) In praise of boredom. Ephemera. Theory and Politics in Organization, 11 (4), 387-405.

JANKÉLEVITCH, V. (1989) La aventura, el aburrimiento, lo serio. Madrid, Taurus.

KANT, I. (1988) Lecciones de Ética. Barcelona, Editorial Crítica.

KierkegaARD, S. (2006) O lo uno o lo otro. Un fragmento de vida I. Madrid, Trotta.

Kirova, A. (2004) Lonely or Bored: Children's Lived Experiences Reveal the Difference. Interchange, 35 (2), 243-268.

Kundera, M. (2012) La identidad. Barcelona, Tusquets.

Lemos Britto, F. (2012) Uma pedagogia da solidão em Nietzsche. Educação e Filosofia Uberlândia, 26 (51), 251-262.

Lewkowich, D. (2010) The Possibilities for a Pedagogy of Boredom. Rethinking the Opportunities of Elusive Learning. Journal of Curriculum Theorizing, 26 (1), 129-143.

MARQuÉs, P. y MAJó, J. (2002) La revolución educativa en la era de internet. Bilbao, Praxis.

Martin, M.; Sadlor, G. y STEW, G. (2006) The phenomenon of boredom. Qualitative Research in Psychology, 3 (3), 193-211.

Nietzsche, F. (2003) La gaya ciencia. Palma de Mallorca, El Barquero.

O'Reilly, T. (2005, 30 de septiembre). What Is Web 2.0 Design Patterns and Business Models for the Next Generation of Software [www.oreilly.com]. Consultado el 17 de junio de 2016. http://www.oreilly.com/pub/a/web2/archive/what-is-web-20.html. 
PARDO, J. L. (1989) La banalidad. Barcelona, Anagrama.

Pascal, B. (1998) Pensamientos. Madrid, Cátedra.

Pekrun, R.; Goetz, T.; Daniels, L. M.; Stupnisky, R. H. y Perry, R. P. (2010) Boredom in achievement settings: exploring control-value antecedents and performance outcomes of a neglected emotion. Journal of Educational Psychology, 102 (3), 531-549.

Peretó Rivas, R. (2011) Acedia y depresión. Apuntes para una reconstrucción histórica. Eäjournal, 3 (1). Consultado el 17 de junio de 2016. http://www.ea-journal.com/art3.1/ Pereto-Rivas-Acedia-y-depresion.pdf.

Prensky, M. (2001) Digital natives, digital immigrants. On the Horizon, 9 (5), 1-6.

RAGHEB, M. G. (2002) El aburrimiento en el tiempo libre. Una patología que puede impedir potenciar al máximo los beneficios de la educación del ocio. Adoz. Revista de Estudios de Ocio, 23, 40-61.

Russell, B. (2003) La conquista de la felicidad. Barcelona, DeBolsillo.

SáncheZ-Mejía, M. L. (1996) Desencanto político y nostalgia del paraíso en los orígenes del «mal du siècle». Revista de Filología Francesa, 9, 247-262.

Schopenhauer, A. (2009) Parerga y Paralipómena. Madrid, Trotta.

SHultz, T. (1971) Investment in Human Capital: The Role of Education and of Research. Nueva York, Free Press.

Silva, R.; GonçAlves, B. y Ferreira, A. (2014) Crianças Mobile: tecnologias móveis e as novas estratégias de marketing infantil. Revista Anagramas, 8 (2). Consultado el 17 de junio de 2016. http://www.revistas.univerciencia.org/index.php/anagrama/article/ viewFile/8714/7975.

Simons, M. y Masschelein, J. (2008) The Governmentalization of Learning and the Assemblage of a Learning Apparatus. Educational Theory, 58 (4), 391-415.

Simons, M. y Masschelein, J. (2014) Defensa de la escuela. Una cuestión pública. Buenos Aires, Miño y Dávila.

Smeyers, P.; De Ruyter, D. J.; Waghid, Y. y Strand, T. (2014) Publish Yet Perish: on the pitfalls of philosophy of education in an age of impact factors. Studies in Philosophy and Education, 33 (6), 647-666.

SMitH, R. P. (1981) Boredom: A Review. Human Factors: The Journal of the Human Factors and Ergonomics Society, 23 (3), 329-340.

SPACKS, P. M. (1995) Boredom: The Literary History of a State of Mind. Chicago, The University of Chicago Press.

Spaeth, M.; Weichold, K. y Silbereisen, R. K. (2015) The development of leisure boredom in early adolescence: Predictors and longitudinal associations with delinquency and depression. Developmental Psychology, 51 (10), 1380-1394.

Steinberg, S. R. y Kincheloe, J. L. (2000) Basta de secretos. Cultura infantil, saturación de información e infancia posmoderna, en Steinberg, S. R. y Kincheloe, J. L. (comps.) Cultura infantil y multinacionales. Madrid, Morata, 15-44.

Svendsen, L. (2006) Filosofía del tedio. Barcelona, Tusquets.

TAPSCOTT, D. (2009) Grown up digital: how the net generation is changing your world. Nueva York, McGraw-Hill

Vodanovich, J. S. (2003) Psychometrics Measures of Boredom: A Review of the Literature. The Journal of Psychology, 137 (6), 569-595.

Vogel-Walcutt, J. J.; Fiorella, L.; Carper, T. y Schatz, S. (2012) The Definition, Assessment and Mitigation of State Boredom Within Educational Settings: A Comprehensive Review. Educational Psychology Review, 24, 89-111. 
Weber, M. (1998) La ética protestante y el espíritu del capitalismo. Madrid, Ediciones Istmo. Wegner, L.; Flisher, A. J.; Chikobvu, P.; Lombard, C. y King, G. (2008) Leisure boredom and high school dropout in Cape Town, South Africa. Journal of Adolescence, 31 (3), 421-431.

Willging, C. E.; Quintero, G. A. y Lilliott, E. A. (2014) Hitting the Wall: Youth Perspectives on Boredom, Trouble, and Drug Use Dynamics in Rural New Mexico. Youth \& Society, $46(1), 3-29$. 